nervous system. For those who are not accustomed to looking at electron microscopic pictures, it is sad that the plates in the chapter on ultrastructural aspects of infections in the central nervous system have not got more labels on the prints to indicate exactly what one is supposed to be looking at. However, the electron microscope prints throughout the book are of high quality. It is useful to have an instructive account on the role pleuro-pneumonia-like organisms may play in neurological disturbances and also an account of infections with histoplasma and cryptococcus. These latter infections are being more frequently diagnosed these days because of greater awareness of their existence. It is also nice to see a chapter on a much too neglected subject 'The Water and Electrolyte Shifts in the Central Nervous System'. A whole range of other infections are covered, mostly of viral aetiology. The fascinating problem of slow, latent, and temperate viruses is well covered, but this brings me to a criticism of the book. This whole field of investigation of infections of the central nervous system has been so rapidly advancing over the last five years that I find it disappointing that what was presented at a meeting in December 1964, should take till 1968 to be published. This must detract from the value of the book and, as the editor, Dr. H. M. Zimmerman, rather sadly comments at the beginning of the chapter on 'Vaccinia Virus Deoxyribonucleic Acid': 'It has not been brought up to date and, therefore, does not take into account the large amount of information which has been obtained during the intervening years as a result of the efforts of many workers in this rapidly developing field.'

This is a very well presented book and will be useful to both research workers and clinicians. There are excellent bibliographies to the chapters throughout. It would have been even more valuable published with less delay, even though it might have lost some of its 'finish' in the process.

H. E. WEBB

A Manual of electroneuromyography By Hyman L. Cohen and Joel Brumlik. (Pp. xi +178 ; illustrated. \$10.50). Hoeber Medical Division, Harper \& Row: New York. 1968.

A good handbook on electromyography and related techniques would be welcome. The senior workers in clinical neurophysiology have grown up with the subject and do not require one, but the new generation of neurologists, orthopaedists, and physical medicine workers do need a good summary of the present state of the art. There is an expanding literature in orthopaedic journals of papers using electromyographic techniques in an entirely uncritical way indicating ignorance of the basic principles. It is for that reason that the present book cannot be recommended. For the complete beginner it gives a step-by-step account of the methods used in electromyography, nerve conduction studies, and older forms of electrodiagnosis, but does not provide the information on neuromuscular physiology, volume conduction theory, and instrumentation to enable an isolated worker to interpret what he sees or even to use another manufacturer's equipment. The illustrations of myotonia and myasthenia are not typical and the latter-which is used twice-suggests failure to ensure that the stimulus was supramaximal and that the hand was immobilized.

The techniques described are those of ten years ago. There is no information on averaging techniques, methods of quantitative electromyography, or even how to reduce the noise level. This is not the handbook we have been waiting for.

J. A. SIMPSON

LECTURE NOTES ON NeUROlogy 2 nd edn. By I. T. Draper. (Pp. ix +231 ; illustrated. 22s. 6d.) Blackwell: Oxford and Edinburgh. 1968.

The second edition, three years after the first, speaks for the popularity of this little book. It is divided into three traditional parts: applied anatomy and physiology, bedside skills, and description of disease. The first two parts, for the purpose of this book, can hardly be faulted. Presumably it is read by undergraduates as a reminder of what they have already learnt, later on special occasions by them in practice, and by teachers of medicine wishing to revise quickly unaccustomed material for tutorials or lectures. For these purposes the book says enough and says it clearly. However, fears must be felt for a reader whose only source of neurological information this might be, and the dust jacket suggests that this might be the case. There is too little indication of the relative frequency of diseases and of their urgency, so that, by inference, the reader might believe that disseminated sclerosis was equalled numerically by syringomyelia or that giant-cell arteritis and vitamin $B_{12}$ neuropathy each carried no more alarm for the doctor than most neurology. To reproduce lecture notes for an already committed audience is one thing; to present them as an introduction is another and, with this volume, not without danger of distortion. There are surprising omissions, too, and ones that could be said to hide important principles and to withhold some of the difficulties of clinical life. For instance, the concept of transient ischaemia of the brain gets insufficient mention and the overwhelming importance of the psychological aspects of pain (particularly facial) are merely hinted at. This kind of deficiency makes for poor remembrancing and a misleading tutor. One understands that the confined space of this small volume demands economy of expression as well as pruning of material, but this should not be achieved at the expense of making such a frail vehicle for those whose journey in clinical neurology is to depend much on this book alone. If this is not possible within these narrow bounds, then let the space be more.

\section{H. EDWARDS}

CRANIOFACIAL ANOMALIES: PATHOGENESIS AND REPAR

Edited by J. J. Longacre. (Pp. xii + 389; illustrated.

170s.) Pitman Medical: London; and J. B. Lippincott: Philadelphia. 1969.

This well-illustrated and attractive book is based on papers presented at an international conference in May 1966. In the preface (unsigned) we are told, in that breathless prose which we have come to recognize, that is was 'the most stimulating, intense and provocative meeting they had ever attempted... a meeting of the 